\title{
Prevalence of Intestinal Parasites in Alcoholics
}

\author{
Akale Pallavi S. ${ }^{1}$, Paranjpe Supriya M. ${ }^{2}$, Koticha Avani H. ${ }^{3}$, Mehta Preeti R. ${ }^{4}$ \\ ${ }^{1}$ Resident, Department of Microbiology, Seth G. S. Medical College and KEM Hospital, \\ Mumbai, Maharashtra, India. \\ ${ }^{2}$ Assistant Professor, Department of Microbiology, Seth G. S. Medical College and KEM Hospital, \\ Mumbai, Maharashtra, India. \\ ${ }^{3}$ Professor, Department of Microbiology, Seth G. S. Medical College and KEM Hospital, \\ Mumbai, Maharashtra, India. \\ ${ }^{4}$ Professor and HOD, Department of Microbiology, Seth G. S. Medical College and KEM Hospital, \\ Mumbai, Maharashtra, India.
}

\section{ABSTRACT}

\section{BACKGROUND}

In developing countries both alcoholism and intestinal parasites are very common. Alcoholism and intestinal parasitic infections go hand in hand, not only due to their unhygienic conditions but also due to damage to immune system. The present study was aimed to find out the prevalence of intestinal parasites amongst alcoholics.

\section{METHODS}

300 alcoholics and non-alcoholics were tested for intestinal parasites. A single stool specimen was collected for detection of intestinal parasites. A saline and iodine mount was examined microscopically to demonstrate the intestinal parasites. Formol ether concentration technique was performed to increase the yield of the eggs and larvae. Water emergence technique and Agar plate culture was performed for Strongyloides stercoralis. Modified Acid Fast staining was done for opportunistic parasitic infections. The categorical outcomes were assessed by Chi Square test.

\section{RESULTS}

The prevalence of intestinal parasites was more in alcoholics (7.66\%) as compared to non-alcoholics (3\%). In alcoholics, among the helminths, Strongyloides stercoralis $(2.6 \%)$ was predominantly seen followed by Ascaris lumbricoides $(0.33 \%)$ and hookworm (0.33\%). Amongst the protozoan parasites, the predominant parasite was Entamoeba histolytica (2.3\%) followed by Blastocystis hominis (1.33\%) and Giardia lamblia (0.6\%). Prevalence of Strongyloides stercoralis had a significant correlation with history of walking barefoot. Eosinophilia was predominantly seen in alcoholics with intestinal parasites.

\section{CONCLUSIONS}

Alcoholics whether symptomatic or asymptomatic should be screened for intestinal parasites especially Strongyloides stercoralis to prevent morbidity. Presence of eosinophilia is a good positive predictive marker for intestinal parasitic infection. All alcoholics should be counselled regarding personal hygiene specially about barefoot walking to prevent infection with Strongyloides stercoralis.

\section{KEY WORDS}

Alcoholism, Intestinal Parasites, Strongyloides stercoralis, Eosinophilia
Corresponding Author:

Dr. Supriya Paranjpe,

Department of Microbiology,

$5^{\text {th }}$ Floor, MSB, Seth G. S. Medical College, KEM Hospital, Mumbai, Maharashtra,

India.

E-mail: supriyamparanjpe@gmail.com

DOI: $10.14260 /$ jemds/2019/568

Financial or Other Competing Interests: None.

How to Cite This Article:

Pallavi AS, Supriya PM, Avani KH, et al. Prevalence of intestinal parasites in alcoholics. J. Evolution Med. Dent. Sci. 2019;8(33):2607-2611, $10.14260 /$ jemds $/ 2019 / 568$

Submission 21-06-2019,

Peer Review 04-08-2019,

Acceptance 10-08-2019,

Published 19-08-2019. 


\section{BACKGROUND}

Intestinal parasites are virtually present worldwide. Ascariasis, amoebiasis, hookworm infection and trichuriasis are amongst the ten most common infections throughout the world.(1) The prevalence of intestinal parasites ranges from $2.5 \%$ to $91 \%$ in developing countries. $(2,3,4,5,6)$ In developing countries both alcoholism and intestinal parasites are very common. Alcoholism and intestinal parasitic infections go hand in hand, not only due to their unhygienic conditions but also due to damage to immune system.(7) Ethanol reduces inflammatory cells as well as alters cytokines leading to prolonged survival of intestinal parasites.(7,8) Immunosuppressive conditions like HIV and HTLV infection, prolonged use of steroids, alcoholism and cytotoxic drugs can accelerate autoinfectious cycle and can cause overwhelming replication of the parasite progressing to hyperinfection or dissemination. $(7,9,10)$ Multiple case studies are published regarding alcoholism being the risk factor for Strongyloides stercoralis infection. ${ }^{(10,11)}$ However, as per Schar et al, the prevalence of Strongyloides stercoralis amongst alcoholics appears to be underestimated.(9) The reason proposed being low sensitive diagnostic test used for detection of Strongyloides stercoralis. ${ }^{(9)}$

The present study was conducted to determine the prevalence of intestinal parasites amongst alcoholics with special reference to Strongyloides stercoralis and to correlate presence of intestinal parasites with factors like age, clinical manifestations, socioeconomic status and presence of eosinophilia.

\section{METHODS}

A cross-sectional study was conducted in a tertiary care multispecialty teaching hospital in Mumbai, India after obtaining institutional ethics committee permission. The sample size was calculated based on prevalence of $26 \%$ from study conducted by Schar et al( 9 ) by which, with $5 \%$ precision, 300 each of the alcoholics (cases) and non-alcoholics (Controls) were recruited in the study. Alcoholics were defined as per the Diagnostic and Statistical Manual of Mental Disorders (DSM) 5 criteria(12) diagnosed by qualified psychiatrist and non-alcoholics were considered as person who do not drink alcohol at all or social drinking of maximum of 1 event per week.

After obtaining an informed written consent, the clinical as well as demographic history was taken as per the case record form. A single stool specimen was collected for detection of parasitic infection in a clean, wide mouth, leak-proof screw capped container. A saline and Iodine mount was prepared and examined microscopically to demonstrate helminthic eggs, motility of protozoan trophozoites and larvae of Strongyloides stercoralis. Saline and Formol ether Concentration technique was performed to increase the yield of the eggs and larvae.

Water emergence technique and Agar plate culture was performed for Strongyloides stercoralis.(13) Modified Acid-Fast staining was done for opportunistic parasitic infections.(14)

\section{Statistical Analysis}

The difference between proportions of two groups was analysed by using Chi-square test. The statistical software SPSS Ver.16 was used to perform the analysis.

\section{RESULTS}

In the present study, the age of study participants ranged from 21 to 50 years with a mean age of 40.3 years. (Table 1 ) There was a positive correlation between eosinophilia and presence of intestinal parasites. $(\mathrm{P}$ value $=0.001)$ (Table 1$)$ There was a significant correlation between lower middle-class economic status and presence of intestinal parasites. $(\mathrm{P}$ value $=0.0067)$ (Table 1) The prevalence of intestinal parasites was significantly more in alcoholics $(7.66 \%)$ as compared to nonalcoholics (3\%). (P value $=0.01)$ (Table 2$)$ In alcoholics, among the helminths, Strongyloides stercoralis (2.6\%) was predominantly seen followed by Ascaris lumbricoides (0.33\%) and hookworm $(0.33 \%)$. Amongst the protozoan parasites, the predominant parasite was Entamoeba histolytica (2.3\%) followed by Blastocystis hominis $(1.33 \%)$ and Giardia lamblia $(0.6 \%)$. (Table 3 ) There was a significant correlation between symptoms and presence of intestinal parasites $(\mathrm{p}$ value $=$ 0.0000001 ) (Table 4) Strongyloides stercoralis was detected in $5(12.20 \%)$ out of 41 alcoholics who gave history of walking barefoot which was statistically significant. $(p$ value $=0.002)$ (Table 5).

\begin{tabular}{|c|c|c|c|c|}
\hline & $\begin{array}{l}\text { Intestinal } \\
\text { Parasites } \\
\text { Detected }\end{array}$ & $\begin{array}{c}\text { Intestinal } \\
\text { Parasites not } \\
\text { Detected }\end{array}$ & Total & p Value \\
\hline \multicolumn{5}{|c|}{ Age (Years) } \\
\hline $21-30$ & $8(12.1 \%)$ & $58(87.9 \%)$ & 66 & \multirow{3}{*}{0.3} \\
\hline $31-40$ & $6(5.8 \%)$ & $98(94.2 \%)$ & 104 & \\
\hline $41-50$ & $9(6.9 \%)$ & $121(93.1 \%)$ & 130 & \\
\hline \multicolumn{5}{|c|}{ Socioeconomic Status (Kuppuswamy Class) } \\
\hline Lower middle class & $13(13.83 \%)$ & $81(86.17 \%)$ & 94 & \multirow{2}{*}{0.0067} \\
\hline Upper middle class & $10(4.85 \%)$ & $196(95.15 \%)$ & 206 & \\
\hline \multicolumn{5}{|c|}{ Eosinophil Count } \\
\hline Normal & $12(4.16 \%)$ & $277(95.84)$ & 289 & \multirow[t]{2}{*}{0.001} \\
\hline Raised & $11(100 \%)$ & $0(0 \%)$ & 11 & \\
\hline \multicolumn{5}{|c|}{$\begin{array}{l}\text { Table 1. Correlation of Age, Socioeconomic Status, Eosinophilia \& } \\
\text { Intestinal Parasites in Alcoholics }\end{array}$} \\
\hline
\end{tabular}

\begin{tabular}{|c|c|c|c|c|}
\hline & $\begin{array}{c}\text { Intestinal Parasites } \\
\text { Detected }\end{array}$ & $\begin{array}{c}\text { Intestinal Parasites } \\
\text { not Detected }\end{array}$ & Total & p Value \\
\cline { 1 - 4 } Alcoholics & $23(7.66 \%)$ & $277(92.34 \%)$ & 300 & \multirow{2}{*}{0.01} \\
\hline $\begin{array}{c}\text { Non- } \\
\text { Alcoholics }\end{array}$ & $9(3 \%)$ & $291(97 \%)$ & 300 & \\
\cline { 1 - 2 } Table 2. Prevalence of Intestinal Parasites in Alcoholics and \\
Non-Alcoholics
\end{tabular}

\begin{tabular}{|c|c|c|c|c|}
\hline & $\begin{array}{c}\text { Intestinal Parasites } \\
\text { Detected }\end{array}$ & $\begin{array}{c}\text { Alcoholics } \\
(\mathbf{n = 3 0 0 )}\end{array}$ & $\begin{array}{c}\text { Non- Alcoholics } \\
(\mathbf{n = 3 0 0 )}\end{array}$ & p Value \\
\hline \multirow{4}{*}{ Helminths } & Strongyloides stercoralis & $8(2.67 \%)$ & $0(0 \%)$ & 0.0075 \\
\cline { 2 - 5 } & Hookworm & $1(0.33 \%)$ & $0(0 \%)$ & 1 \\
\cline { 2 - 5 } & Ascaris lumbricoides & $1(0.33 \%)$ & $0(0 \%)$ & 1 \\
\cline { 2 - 5 } Protozoa & Hymenolepis nana & $0(0 \%)$ & $1(0.33 \%)$ & 1 \\
\cline { 2 - 5 } & Entamoeba histolytica & $7(2.33 \%)$ & $3(1 \%)$ & 0.20 \\
\cline { 2 - 5 } & Blastocystis hominis & $4(1.33 \%)$ & $2(0.67 \%)$ & 0.41 \\
\cline { 2 - 5 } Total & Giardia lamblia & $2(0.67 \%)$ & $3(1 \%)$ & 0.65 \\
\hline \multicolumn{5}{|c|}{ Table 3. Distribution of Intestinal Parasites in } \\
\hline \multicolumn{5}{|c|}{ Alcoholics and Non-Alcoholics } \\
\hline
\end{tabular}

\begin{tabular}{|c|c|c|c|c|}
\hline & $\begin{array}{c}\text { Intestinal } \\
\text { Parasites Detected }\end{array}$ & $\begin{array}{c}\text { Intestinal Parasites } \\
\text { not Detected }\end{array}$ & Total & p Value \\
\hline Symptomatic & $13(54.17 \%)$ & $11(45.83 \%)$ & 24 & \multirow{2}{*}{0.000001} \\
\hline Asymptomatic & $10(3.62 \%)$ & $266(96.38 \%)$ & 276 & 0.300 \\
\hline Total & $23(7.66 \%)$ & $277(92.34 \%)$ & 300 & \\
\hline \multicolumn{4}{|c|}{ Table 4. Correlation of Clinical Manifestations and } \\
Intestinal Parasites in Alcoholics \\
\hline
\end{tabular}




\begin{tabular}{|c|c|c|c|c|}
\hline $\begin{array}{c}\text { History of Walking } \\
\text { Barefoot }\end{array}$ & $\begin{array}{c}\text { Strongyloides } \\
\text { stercoralis } \\
\text { Detected }\end{array}$ & $\begin{array}{c}\text { Strongyloides } \\
\text { stercoralis } \\
\text { Not Detected }\end{array}$ & Total & $\begin{array}{c}\mathbf{p} \\
\text { Value }\end{array}$ \\
\hline Barefoot walker & $5(12.20 \%)$ & $36(87.80 \%)$ & 41 & 0.002 \\
\hline Non-barefoot walkers & $3(1.16 \%)$ & $256(98.84)$ & 259 & \\
\hline Total & $8(2.66 \%)$ & $292(97.34 \%)$ & 300 & \\
\hline Table 5. Correlation of Barefoot Walking and \\
Strongyloides stercoralis in Alcoholics \\
\hline
\end{tabular}

\section{DISCUSSION}

Alcohol consumption, especially heavy drinking, is an important risk factor for many health problems and thus, is a major contributor to the global burden of diseases.(15) Infections are more frequent and severe amongst the alcoholics probably due to dulled mental function, breakdown of local protective barriers, aspiration, exposure to pathogens and malnutrition.(16) Immunosuppressive conditions like HIV, HTLV infection, prolonged steroid use, alcoholism and cytotoxic drugs(17) can accelerate autoinfection and cause an overwhelming replication of parasite progressing to hyperinfection or dissemination which can be fatal. Early detection of the presence of these larvae in the stool specimen will prevent spread of these larvae to the lungs and further complications.

In the present study the prevalence of intestinal parasites was more in the age group of 21-30 years, as compared to other age groups. But there was no significant predilection of any age group to intestinal parasite in both groups. (Table 1) A similar finding was reported in the study by Gomes et al.(7) There was a high prevalence of intestinal parasites in low socioeconomic areas. (Table 1) Dhanabal et al have reported a similar finding from south Chennai.(18) It is expected that people from low socioeconomic status have lesser access to clean water supply and sanitary facilities. Also, lack of education and awareness regarding hygienic practices may be responsible for higher prevalence of intestinal parasites in this group. Intestinal parasites were detected in all patients with eosinophilia which was statistically significant. (Table 1) Many studies have evaluated the importance of presence of eosinophilia in diagnosis of Strongyloides stercoralis. Loutfey MR et al have suggested that eosinophilia can be used as a potential useful marker for the diagnosis of the infection.(19) Sanchez et al and Gill et al have reported presence of eosinophilia as the only indicator of Strongyloides stercoralis infection. This highlights the fact that the presence of eosinophilia should indicate stool screening for intestinal parasites to prevent the further morbidity in already morbid alcoholic patients. In the present study the prevalence of intestinal parasites in alcoholics (7.6\%) was significantly higher as compared to the non-alcoholic group (3\%). (Table 2) Gomes et al (7) and Avendano et al have also reported a high prevalence of intestinal parasitism in alcoholics.(20) There was a high prevalence of Strongyloides stercoralis (2.66\%) in alcoholic group as against absence of Strongyloides stercoralis in non-alcoholic group (Table 3). High prevalence of Strongyloides stercoralis infection in alcoholics may be due to higher predisposition to infections due to poor hygiene conditions like walking barefoot, evacuation in their clothes or lack of hygiene following the evacuation.
Another reason could be breakdown of immune defences to eliminate the parasites which could occur at the level of intestinal mucosa, the cell mediated and/ humoral immunity or the compliment system.(30) Various studies have similarly, reported a higher frequency of Strongyloides stercoralis in alcoholics as compared to non-alcoholics. $(7,20,21)$ Adedayo et al reported 27 cases of hyperinfection and found that $44 \%$ of the patients had a history of chronic alcoholism which was a relevant factor associated with poor prognosis of Strongyloides stercoralis infection.(22) Silva et al conducted a study in HIV/AIDS patients and observed that out of the infected patients who reported to be chronic alcoholics, $64.3 \%$ had strongyloidiasis.(23) Kuyare et al have also reported the presence of alcoholism as a risk factor in $56 \%$ of patients with strongyloidiasis.(24)

Out of the total $7.6 \%$ of intestinal parasites detected in alcoholics in the present study, protozoans predominated (4.3\%) followed by 3.3\% helminths. (Table 3) There was no significant difference between the prevalence of intestinal parasites other than Strongyloides stercoralis in alcoholic and non-alcoholic group. Similar finding was reported by Gomes et al.(7) In the present study, the prevalence of Entamoeba histolytica in alcoholics was $2.3 \%$ which was more as compared to non-alcoholics (1\%) (Table 3) Entamoeba histolytica is the third leading cause of parasite related deaths in the world.(25) The spectrum of diseases caused by this protozoan includes intestinal as well as extra intestinal manifestations mostly in the form of amoebic liver abscess.(26) Chronic alcoholism seems to predispose to amoebic liver abscess as seen by the fact that most amoebic liver abscess cases occur in people who consume regular alcohol.(27,28,29,30) In the past experimental studies have shown that iron acts as growth factor for Entamoeba histolytica. ${ }^{(31,32)}$ It is known that alcohol influences the absorption of iron ${ }^{(33)}$ and the metabolic effects of chronic alcohol consumption include an increase in the liver iron content, thus potentiating the growth of Entamoeba histolytica in the liver.(34) It has been reported that, $10 \%$ of the world's population are infected with Entamoeba species in which pathogenic Entamoeba histolytica constitute only $10 \%$ of these infections and the remaining $90 \%$ are infected by non-pathogenic Entamoeba dispar.(35) Routine microscopy cannot differentiate between pathogenic Entamoeba histolytica and non-pathogenic Entamoeba dispar. Molecular analysis is needed to differentiate between the two. Hence, careful history taking, and clinical correlation is required if Entamoeba histolytica or Entamoeba dispar is detected in the specimen and needs to be treated accordingly.

There is a strong correlation between prevalence of Blastocystis hominis and presence of irritable bowel syndrome.(36) Also, Blastocystis hominis is associated with malabsorption syndrome (37) which can lead to increase in morbidity of alcoholics. Though the prevalence of Blastocystis hominis in alcoholics was $1.3 \%$ which was not statistically different from non-alcoholics. The alcoholics with Blastocystis hominis infection should be followed up for the signs and symptoms of irritable bowel.

In the present study, the prevalence of Ascaris lumbricoides was reported to be $0.33 \%$ in alcoholics as against absence of Ascaris lumbricoides in non-alcoholic group. (Table 3) Ascaris lumbricoides can cause malnutrition by consumption of nutrients which are needed by the host; interference with intestinal absorption due to mucosal damage by the parasite; 
it can cause protein energy malnutrition and night blindness due to vitamin A deficiency.(37) The presence and extent of protein calorie malnutrition play an important role in determining the outcome of patients with alcoholic liver disease. Mortality increases in direct proportion to the extent of malnutrition, approaching $80 \%$ in patients with severe malnutrition.(38) Micronutrient abnormalities, such as hepatic vitamin A depletion or depressed vitamin E levels, may also potentially aggravate liver disease.(39) Hence the treatment of alcoholics with Ascaris lumbricoides should be done to prevent further complications.

Hookworm infection is usually acquired by walking barefoot on fecally contaminated soil or by accidentally drinking water contaminated with filariform larvae.(37) Schmidin et al have shown a positive correlation between outdoor defecation and prevalence of soil transmitted helminths. ${ }^{(40)}$ The adult worms inhabit the small intestine, attaching themselves to the mucous membrane of the intestine. In a course of time, a severe progressive anaemia of microcytic hypochromic type develops.(37) Alcohol has various adverse effects on the types of blood cells and their functions such as generalized suppression of production of blood cell, production of structurally abnormal blood cell precursors that cannot mature into functional cells and defective red blood cells that are destroyed prematurely, possibly resulting in anaemia.(41) Even though the prevalence of hookworm was low in the study, to prevent the aggravation of anaemia it can be recommended that the alcoholics needs to be screened for hookworm infection and treated for the same.

In the present study there was a significant correlation between the symptoms and presence of intestinal parasites. (Table 4) In a retrospective study conducted by Kuyare et al, it was reported that the commonest complaint in Strongyloides stercoralis infection was diarrhoea followed by breathlessness, whereas one fifth of patients were asymptomatic.(24) In a study conducted in an adult population Becker et al reported the following symptoms in patients infected with Strongyloides stercoralis: $40.5 \%$ complained of abdominal pain, $18.9 \%$ had diarrhoea, $32.4 \%$ passed blood in stool, $27 \%$ had cough, $16.2 \%$ had skin rashes and $16.2 \%$ had pruritis. ${ }^{(42)}$

As the mode of infection of Strongyloidiasis is penetration of intact skin, we evaluated barefoot walking and frequency of Strongyloides stercoralis. In the present study, Strongyloides stercoralis was detected in $5(12.20 \%)$ out of 41 alcoholics who gave the history of walking barefoot. (Table 5) One alcoholic patient with hookworm infection also gave history of walking barefoot.

In a study conducted in Nepal, Sah et al observed that regular wearing of sandals or shoes had a significantly lower prevalence of parasitic infections i.e. $3.2 \%$ as compared to those who did not wear sandals or shoes which was $26.2 \% .{ }^{(43)}$ Similarly, in a study conducted by Cremades et al 30 of the 37 positive cases for Strongyloides stercoralis (81\%) had history of walking barefoot.(44) Shcmidiin et al have also noted a positive correlation between walking barefoot and prevalence of Strongyloides stercoralis and hookworm.(40) This suggests that the alcoholics should be counselled about their personal hygiene including, avoiding walking barefoot to prevent infections with soil transmitted helminths like Strongyloides stercoralis.

\section{CONCLUSIONS}

All alcoholics whether symptomatic or asymptomatic should be screened for intestinal parasites especially Strongyloides stercoralis to prevent morbidity. Presence of eosinophilia is a good positive predictive marker for intestinal parasitic infection. All the alcoholics should be counselled regarding personal hygiene, specially about barefoot walking to prevent infection with Strongyloides stercoralis.

\section{REFERENCES}

[1] Prevention and control of intestinal parasitic infections: WHO Technical Report Series $N^{\circ}$ 749. World Health Organization, 1987 [cited 10 January 2017]. http://www.who.int/neglected_diseases/resources/wh o_trs_749/en/

[2] Mohan S, Karthikeyan D. Prevalence of intestinal parasitic infection among school going children in Karaikal. Asia Pacific Journal of Research 2016;2(37):181-6.

[3] Nitin S, Venkatesh V, Husain $N$, et al. Overview of intestinal parasitic prevalence in rural and urban population in Lucknow, north India. The Journal of Communicable Diseases 2007;39(4):217-23.

[4] Fernandez MC, Verghese S, Bhuvaneswari R, et al. A comparative study of the intestinal parasites prevalent among children living in rural and urban settings in and around Chennai. The Journal of Communicable Diseases 2002;34(1):35-9.

[5] Sehgal R, Reddy GV, Verweij JJ, et al. Prevalence of intestinal parasitic infections among school children and pregnant women in a low socio-economic area, Chandigarh, North India. RIF 2010;1(2):100-3.

[6] Wani SA, Ahmad F, Zargar SA, et al. Intestinal helminths in a population of children from the Kashmir valley, India. Journal of Helminthology 2008;82(4):313-7.

[7] Zago-Gomes MP, Aikawa KF, Perazzio SF, et al. Prevalence of intestinal nematodes in alcoholic patients. Revista da Sociedade Brasileira de Medicina Tropical 2002;35(6):571-4.

[8] Genta RM. Dysregulation of strongyloidiasis: a new hypothesis. Clin Microbiol Rev 1992;5(4):345-55.

[9] Schär F, Trostdorf U, Giardina F, et al. Strongyloides stercoralis: global distribution and risk factors. PLoS Negl Trop Dis 2013;7(7):e2288.

[10] Chordia P, Christopher S, Abraham OC, et al. Risk factors for acquiring Strongyloides stercoralis infection among patients attending a tertiary hospital in south India. Indian Journal of Medical Microbiology 2011;29(2):14751.

[11] Teixeira MC, Pacheco FT, Souza JN, et al. Strongyloides stercoralis infection in alcoholic patients. Article ID 4872473, Biomed Research International 2016;2016:111.

[12] American Psychiatric Association. DSM 5. American Psychiatric Association, May 27, 2013. 
[13] Getaneh A, Medhin G, Shimelis T. Cryptosporidium and Strongyloides stercoralis infections among people with and without HIV infection and efficiency of diagnostic methods for Strongyloides in Yirgalem Hospital, southern Ethiopia. BMC Research Notes 2010;3:90.

[14] Garcia LS. Clinical microbiology procedures handbook. $3^{\text {rd }}$ edn. Washington (DC): ASM Press 2010.

[15] Rehm J. The risks associated with alcohol use and alcoholism. Alcohol research \& health: the journal of the National Institute on Alcohol Abuse and Alcoholism. 2011;34(2):135.

[16] McGregor RR. Alcohol and immune defense. JAMA 1986;256(11):1474-9.

[17] Marcos LA, Terashima A, DuPont HL, et al. Strongyloides hyperinfection syndrome: an emerging global infectious disease. Transactions of the Royal Society of Tropical Medicine and Hygiene 2008;102(4):314-8.

[18] Dhanabal J, Selvadoss PP, Muthuswamy K. Comparative study of the prevalence of intestinal parasites in low socioeconomic areas from South Chennai, India. Article ID 630968, Journal of Parasitology Research 2014;2014:1-7.

[19] Loutfy MR, Wilson M, Keystone JS, et al. Serology and eosinophil count in the diagnosis and management of strongyloidiasis in a non-endemic area. The American Journal of Tropical Medicine and Hygiene 2002;66(6):749-52.

[20] Avendaño L, Hernández F, Jiménez F, et al. Strongyloides stercoralis en pacientes alcohólicos. Parasitología al día 1999;23(3-4):91-4.

[21] De Oliveira LC, Ribeiro CT, Mendes DD, et al. Frequency of Strongyloides stercoralis infection in alcoholics. Memórias do Instituto Oswaldo Cruz 2002;97(1):119-21.

[22] Adedayo O, Grell G, Bellot P. Hyperinfective strongyloidiasis in the medical ward: review of 27 cases in 5 years. Southern Medical Journal 2002;95(7):711-6.

[23] Da Silva CV, Ferreira MS, Borges AS, et al. Intestinal parasitic infections in HIV/AIDS patients: experience at a teaching hospital in central Brazil. Scandinavian Journal of Infectious Diseases 2005;37(3):211-5.

[24] Kuyare SS, Koticha AH, Mehta PR. Strongyloides stercoralis and its risk factors: an experience at a tertiary care hospital. Journal of Evolution of Medical and Dental Sciences (JEMDS) 2016;5(50):3199-202.

[25] Walsh JA. Prevalence of Entamoeba histolytica infection. In: Ravdin JI, edr. Amebiasis: human infection by Entamoeba histolytica. New York: Churchill Livingstone 1988: p. 93-105.

[26] Hughes MA, Petri WA Jr. Amebic liver abscess. Infectious disease clinics of North America. 2000;14(3):565-82, viii.

[27] Anderson HH, Bostick WL, Johnstone HG, et al. Amebiasis, pathology, diagnosis and chemotherapy. Springfield, Illinois: Charles C Thomas Publisher 1953.

[28] Ramachandran S, Sivalingham S, Perumal JR. Hepatic amoebiasis in Ceylon. Journal of Tropical Medicine and Hygiene 1972;75(2):23-33.
[29] Canagaretna C. Amoebic liver abscess-a clinical study. Ceylon Medical Journal 1974;19(1):18-27.

[30] Hai AA, Singh A, Mittal VK, et al. Amoebic liver abscess. Review of 220 cases. International Surgery 1991;76(2):81-3.

[31] Smith JM, Meerovitch E. Specificity of iron requirements of Entamoeba histolytica in vitro. Arch Invest Med (Mex) 1982;13(Suppl 3):63-9.

[32] Makkar RP, Sachdev GK, Malhotra V. Alcohol consumption, hepatic iron load and the risk of amoebic liver abscess: a case-control study. Internal Medicine 2003;42(8):644-9.

[33] Chapman RW, Morgan MY, Boss AM, et al. Acute and chronic effects of alcohol on iron absorption. Digestive Diseases and Sciences 1983;28(4):321-7.

[34] Lundvall O, Weinfeld A, Lundin P. Iron stores in alcohol abusers. Acta Media Scandinavica 1969;185(1-6):259-69.

[35] Ngui R, Angal L, Fakhrurrazi SA, et al. Differentiating Entamoeba histolytica, Entamoeba dispar and Entamoeba moshkovskii using nested polymerase chain reaction (PCR) in rural communities in Malaysia. Parasites \& Vectors 2012;5(1):187.

[36] Mehta RS, Koticha AH, Kuyare SS, et al. Are we neglecting Blastocystis hominis in patients having irritable bowel syndrome. JEMDS 2015;4(64):11164-71.

[37] Chatterjee KD. Parasitology: protozoology and helminthology. 13 $3^{\text {th }}$ edn. New Delhi: CBS Publishers 1957.

[38] Mendenhall C, Roselle GA, Gartside P, et al. Relationship of protein calorie malnutrition to alcoholic liver disease: a re-examination of data from two Veterans Administration Cooperative Studies. Alcoholism Clinical and Experimental Research 1995;19(3):635-41.

[39] Leevy CM, Moroianu SA. Nutritional aspects of alcoholic liver disease. Clin Liver Dis 2005;9(1):67-81.

[40] Schmidlin T, Hürlimann E, Silué KD, et al. Effects of hygiene and defecation behavior on helminths and intestinal protozoa infections in Taabo, Côte d'Ivoire. PLoS One 2013;8(6):e65722.

[41] Ballard HS. The hematological complications of alcoholism. Alcohol Health and Research World 1997;21(1):42-52.

[42] Becker SL, Sieto B, Silué KD, et al. Diagnosis, clinical features, and self-reported morbidity of Strongyloides stercoralis and hookworm infection in a co-endemic setting. PLoS Negl Trop Dis 2011;5(8):e1292.

[43] Sah RB, Baral R, Shah U, et al. A study of prevalence of intestinal helminthic infections and associated risk factors among the school children of Biratnagar submetropolitan, eastern region of Nepal. Int J Curr Res Med Sci 2016;2(4):8-15.

[44] Cremades RM, Igual AR, Ricart OC, et al. Infection by Strongyloides stercoralis in the county of Safor, Spain. Medicina Clínica 1997;109(6):212-5. 